\title{
Electrosynthesized Ni-Al Layered Double Hydroxide-Pt Nanoparticles as an Inorganic Nanocomposite and Potentate Anodic Material for Methanol Electrooxidation in Alkaline Media
}

\author{
Biuck Habibi*, Serveh Ghaderi \\ Electroanalytical Chemistry Laboratory, Department of Chemistry, Faculty of Sciences, \\ Azarbaijan Shahid Madani University, Tabriz, Iran
}

Received: 30th March 2016; Revised: 29th July 2016; Accepted: 9th September 2016

\section{Abstract}

In this study, Ni-Al layered double hydroxide (LDH)-Pt nanoparticles (PtNPs) as an inorganic nanocomposite was electrosynthesized on the glassy carbon electrode (GCE) by a facile and fast two-step electrochemical process. Structure and physicochemical properties of PtNPs/Ni-Al LDH/GCE were characterized by X-ray diffraction, scanning electron microscopy, energy dispersive X-ray spectrometry and electrochemical methods. Then, electrocatalytic and stability characterizations of the PtNPs/Ni-Al LDH/GCE for methanol oxidation in alkaline media were investigated in detail by cyclic voltammetry, chronoamperometry, and chronopotentiometry measurements. PtNPs/Ni-Al LDH/GCE exhibited higher electrocatalytic activity than PtNPs/GCE and Ni-Al LDH/GCE. Also, the resulted chronoamperograms indicated that the PtNPs/Ni-Al LDH/GCE has a better stability. Copyright (c) 2017 BCREC GROUP. All rights reserved

Keywords: Ni-Al layered double hydroxide; Pt nanoparticles; inorganic nanocomposite; electrodeposition; electrooxidation; methanol; fuel cell

How to Cite: Habibi, B., Ghaderi, S. (2017). Electrosynthesized Ni-Al Layered Double Hydroxide-Pt Nanoparticles as an Inorganic Nanocomposite and Potentate Anodic Material for Methanol Electrooxidation in Alkaline Media. Bulletin of Chemical Reaction Engineering \& Catalysis, 12(1): 1-13 (doi:10.9767/bcrec.12.1.460.1-13)

Permalink/DOI: http://dx.doi.org/10.9767/bcrec.12.1.460.1-13

\section{Introduction}

Fuel cells (FCs) as the electrocatalytic energy conversion devices are expected to play a main role in the development of sustainable technologies that mitigate the global warming and the pollution of fossil fuels [1,2]. Due to the increasing energy demand from modern manufacture industry, all intermediate processes required for production and integration of a prod-

\footnotetext{
* Corresponding Author.

E-mail: B.Habibi@azaruniv.ac.ir

Telp./Fax : +98-41-34327541
}

uct's components, FCs have become the promising energy conversion apparatus for powering portable electronics and vehicles [3,4]. FCs powered vehicles are currently under development world-wide in an attempt to diminish the emissions of green-house gas $\left(\mathrm{CO}_{2}\right)$ as well as other noxious gases, such as $\mathrm{NO}_{\mathrm{x}}, \mathrm{SO}_{\mathrm{x}}, \mathrm{CO}$, and hydrocarbons from the transport area $[5,6]$. The direct alcohol fuel cells (DAFCs), belong to the family of fuel cells that where the fuel, alcohol, is fed directly to the FCs, are favorable power devices due to their low operating temperature, simple transportation and fuel storage, high energy efficiency, low exhaustion and 
fast start-up [7,8]. On the other hand, alkaline fuel cells (AFCs) with electrolytes, such as $\mathrm{KOH}$ and $\mathrm{NaOH}$ aqueous solution, show a higher performance in popular low temperature FCs such as polymer electrolyte membrane fuel cells (PEMFCs) and DAFCs [9,10]. It was reported that alcohol oxidation kinetics was improved by using alkaline medium [11]. Research and development activities on the DAFCs in alkaline media have increased extremely in recent years [11-15]. Alkaline DAFCs have drawn specific attention in this area for the advantage of high alcohol oxidation kinetics and of the potential use of cheaper non-Pt electrocatalysts [16]. Among various alcohols used for FCs, methanol is considered one of the most promising alternative fuels from a non-petroleum source. The electrochemical process of direct methanol fuel cells (DMFCs) is a coupled process of electrochemical reactions and transport phenomena of ions and methanol occurring simultaneously in a complex procedure [17-19].

In the recent years, inorganic layered materials have attracted growing interest for use in various fields owing to their favorable properties, including low cost, high thermal stability and suitable catalytic activity [20-22]. Layered double hydroxides (LDH) belong to a class of anionic clay or hydrotalcite-like clays consist of stacked brucite-type octahedral layers with anions and water molecules occupying the interlayer spaces, family providing numerous applications due to their unique physicochemical properties [23-25]. The $\left[\mathrm{M}^{\mathrm{II}_{1-\mathrm{x}}} \mathrm{M}^{\mathrm{II}} \mathrm{x}(\mathrm{OH})_{2}\right]\left[\left(\mathrm{A}^{\mathrm{n}}\right.\right.$ )$_{\mathrm{x} / \mathrm{n}} \cdot \mathrm{mH}_{2} \mathrm{O}$ ], where $\mathrm{M}^{\mathrm{II}}$ is a divalent cation, such as $\mathrm{Ni}^{2+}, \mathrm{Mg}^{2+}$, etc., and $\mathrm{M}$ III is a trivalent cation, such as $\mathrm{Al}^{3+}, \mathrm{Fe}^{3+}$, etc., and $\mathrm{A}^{\mathrm{n}-}$ is an anion, such as $\mathrm{CO}_{3}{ }^{2-}, \mathrm{Cl}$, etc., is a general formula for $\mathrm{LDH}[26,27]$. In particular, the $\mathrm{LDH}$ containing transition metal ions in the lattice of theirs octahedral layer with redox properties, such as $\mathrm{Cu}, \mathrm{Ni}$ and $\mathrm{Fe}$, have been widely synthesized and exploited in many practical catalytic applications [19,28]. Ni-Al LDH not only possess all the advantages of common $\mathrm{LDH}$ but also have the electrochemical activity because of the presence of a reversible one-electron redox couple, $\mathrm{Ni}(\mathrm{III}) / \mathrm{Ni}(\mathrm{II})$, which allows their application in electrochemistry area [29-31]. Electrochemical applications of $\mathrm{LDH}$ to electrochemical sensors, electrocatalysts, dye-sensitized solar cells and super capacitors were presented [32-37]. In the fuel cell applications, recently $\mathrm{Ni}-\mathrm{Al} \mathrm{LDH}$ has been reported to catalyze the electrooxidation of primary alcohols and sugars [38-41].

Different approaches were used to synthesis of $\mathrm{LDH}$ and different methods have been pro- posed to modify electrode surfaces with $\mathrm{LDH}$ films; the most common one consists of depositing a fixed amount of a colloidal solution of the LDH, previously synthesized in bulk size [36,37], onto the electrodes [38-41]. A drawback of this method is the poor adhesion of the $\mathrm{LDH}$ films to the electrode surfaces. To overcome the above problem and to broaden the application of the LDH film modified electrodes recently the electrochemical deposition of $\mathrm{LDH}$ films was carried out to electrosynthesized welladhered thin films of $\mathrm{LDH}$ on electrode materials [41-44]. The great advantages of the electrochemical methods are the short time needed to modify the electrodes surface and excellent application in electrochemistry; whereas a drawback is that the electrodeposited materials have a poor crystallinity [44-47].

In the present investigation, we have prepared the Ni-Al LDH-Pt nanoparticles (PtNPs) as an inorganic nanocomposite on the glassy carbon electrode (GCE) by a two-step electrodeposition process: (i) Ni-Al LDH film was fabricated by an electrodeposition in the first step, and (ii) the PtNPs were precipitated electrochemically on/in the $\mathrm{Ni}-\mathrm{Al} \mathrm{LDH}$ film on the GCE from $\mathrm{H}_{2} \mathrm{PtCl}_{6} .5 \mathrm{H}_{2} \mathrm{O}$ solution in the second step. Then, the structure and physicochemical properties of the $\mathrm{PtNP} / \mathrm{Ni}-\mathrm{Al} \mathrm{LDH} / \mathrm{GCE}$ were attentively characterized and the electroactivity and stability of the PtNPs/Ni-Al LDH/GCE toward methanol oxidation in $\mathrm{NaOH}$ solution was investigated by cyclic voltammetry, chronoamperometry, and chronopotentiometry methods. The electrochemical measurements show that the PtNPs/Ni-Al LDH/GCE has superior catalytic activity for methanol electrooxidation compared to the PtNPs/GCE and Ni-Al LDH/GCE. Also, the chronoamperometric result indicates that the $\mathrm{PtNPs} / \mathrm{Ni}-\mathrm{Al}$ LDH/GCE has a better stability.

\section{Materials and Method}

\subsection{Reagents and apparatus}

$\mathrm{H}_{2} \mathrm{PtCl}_{6} .5 \mathrm{H}_{2} \mathrm{O}, \quad \mathrm{KNO}_{3}, \quad \mathrm{Al}\left(\mathrm{NO}_{3}\right)_{3} .9 \mathrm{H}_{2} \mathrm{O}$, $\mathrm{Ni}\left(\mathrm{NO}_{3}\right)_{2} .6 \mathrm{H}_{2} \mathrm{O}$, methanol and $\mathrm{NaOH}$ with pure analytical grade were purchased from Merck and used as received. All solutions were prepared with doubled distilled water.

X-ray powder diffraction (XRD) patterns were recorded by a Bruker AXS model D8 Advance (Karlsruhe, Germany) instrument, using $\mathrm{Cu}-\mathrm{Ka}$ radiation source $(1.54 \AA)$ at $40 \mathrm{kV}$ and $35 \mathrm{~mA}$ at room temperature. The $2 \theta$ angle of the diffractometer was stepped from $10^{\circ}$ to $90^{\circ}$ at a scan rate of $5 \mathrm{~min}^{-1}$. The morphology of electrodes surface was investigated using scan- 
ning electron microscopy (SEM) on A LEO1430 vp (Carl Zeiss, Germany) instrument equipped with an energy dispersion X-ray spectroscopy (EDX) device. The electrochemical measurements were carried out with an AUTOLAB PGSTAT-100 (potentiostat / galvanostat) equipped with a USB electrochemical interface and controlled by GEPS software. A conventional three-electrode system was employed comprising a modified GCE as working electrode, a platinum wire as counter electrode and an aqueous saturated calomel electrode (SCE) as reference electrode.

\subsection{Preparation of electrocatalyst}

Electrodeposition is an efficient method for the preparation of nanoparticles, has been used to fabricate LDH films on the metal or other substrates [42-44,48,50-52]. It is widely used with different procedures, such as potential step deposition, cyclic voltammetry, doublepulse, and galvanostatic methods [49]. Among these, potential step deposition provides a tool to fine-tune the amount of the deposited materials, the number of active sites and their size. In this work, prior to the electrodeposition and the modification process, the bare GCE was carefully polished with alumina slurry on fine abrasive paper and then entirely cleaned ultrasonically in solution of containing ethanol and doubled distilled water. The electrodeposition processes were performed by using the potentiostatic deposition. Firstly, the Ni-Al LDH film on the GCE was constructed by cathodic reduction in a solution containing $22.5 \mathrm{mM} \mathrm{Ni}\left(\mathrm{NO}_{3}\right)_{2}$, $7.5 \mathrm{mM} \mathrm{Al}\left(\mathrm{NO}_{3}\right)_{3}$ and $0.3 \mathrm{M} \mathrm{KNO}_{3}$ at the applied potential of $-0.9 \mathrm{~V}$ vs. SCE [50]. The reactions are shown as follows [51].

- Nitrate reduction reaction:

$$
\mathrm{NO}_{3}+\mathrm{H}_{2} \mathrm{O}+2 \mathrm{e} \rightarrow \mathrm{NO}_{2}+2 \mathrm{OH} ; \quad \mathrm{E}_{0}=0.01 \mathrm{~V}
$$

- Hydrogen evolution:

$$
2 \mathrm{H}_{2} \mathrm{O}+2 \mathrm{e} \rightarrow \mathrm{H}_{2}+2 \mathrm{OH} ; \quad \mathrm{E}_{\mathrm{o}}=-0.83 \mathrm{~V}
$$

Both reactions can potentially lead to the deposition of LDH by causing a steep local increase in the $\mathrm{pH}$ close to the cathode (GCE) as [52]:

$$
\begin{aligned}
& (1-\mathrm{x}) \mathrm{Ni}^{2+}+\mathrm{xAl}^{3+}+2 \mathrm{OH}^{-}+\mathrm{xNO}_{3}+\mathrm{mH}_{2} \mathrm{O} \rightarrow \\
& {\left[\mathrm{Ni}_{1-\mathrm{x}} \mathrm{Al}_{\mathrm{x}}(\mathrm{OH})_{2}\right]^{\mathrm{x}+}\left(\mathrm{NO}_{3}\right)_{\mathrm{x}} \cdot \mathrm{mH}_{2} \mathrm{O}(\mathrm{LDH})}
\end{aligned}
$$

The obtained Ni-Al LDH/GCE was rinsed with double distilled water. Then, the PtNPs were electrodeposited on/in the $\mathrm{Ni}-\mathrm{Al}$ LDH/GCE by cathodic reduction of an aqueous solution of $0.1 \mathrm{M} \mathrm{H}_{2} \mathrm{SO}_{4}$ containing $1 \mathrm{mM}$
$\mathrm{H}_{2} \mathrm{PtCl}_{6} .5 \mathrm{H}_{2} \mathrm{O}$ at the applied potential of $-0.2 \mathrm{~V}$ vs. SCE [49,53]. The reaction is shown as:

$$
\mathrm{PtCl}_{6}{ }^{2-}+4 \mathrm{e}^{-} \rightarrow \mathrm{PtNPs}+6 \mathrm{Cl}^{-}
$$

\section{Results and Discussion}

\subsection{Physicochemical characterization}

XRD technique is a very strong instrumental method for characterizing the structure and crystallinity of materials. XRD analysis was used to characterize the structure and phase of the PtNPs/Ni-Al LDH/GCE and other materials, and the corresponding resulted patterns were shown in Figure 1. Figure 1 shows XRD patterns of bare GCE (A), PtNPs/GCE (B), Ni$\mathrm{Al} \mathrm{LDH/GCE} \mathrm{(C)} \mathrm{and} \mathrm{PtNPs/Ni-Al} \mathrm{LDH/GCE}$ (D), respectively. As can be seen at the bare GCE, only an intense reflection peak located on the $2 \theta$ angle of $26.4^{\circ}$ was observed, indicating a basic (002) reflection of GCE [53]. While after coating the GCE surface with PtNPs, the XRD pattern of the PtNPs/GCE (Figure 1B) presents the main characteristic peaks of the facecentered cubic (fcc) crystalline Pt at $2 \theta=39.9^{\circ}$, $46.4^{\circ}, 67.6^{\circ}$ and $81.7^{\circ}$, corresponding to the (111), (200), (220) and (311) planes of a face centered cubic (fcc) lattice of Pt nanoparticles,

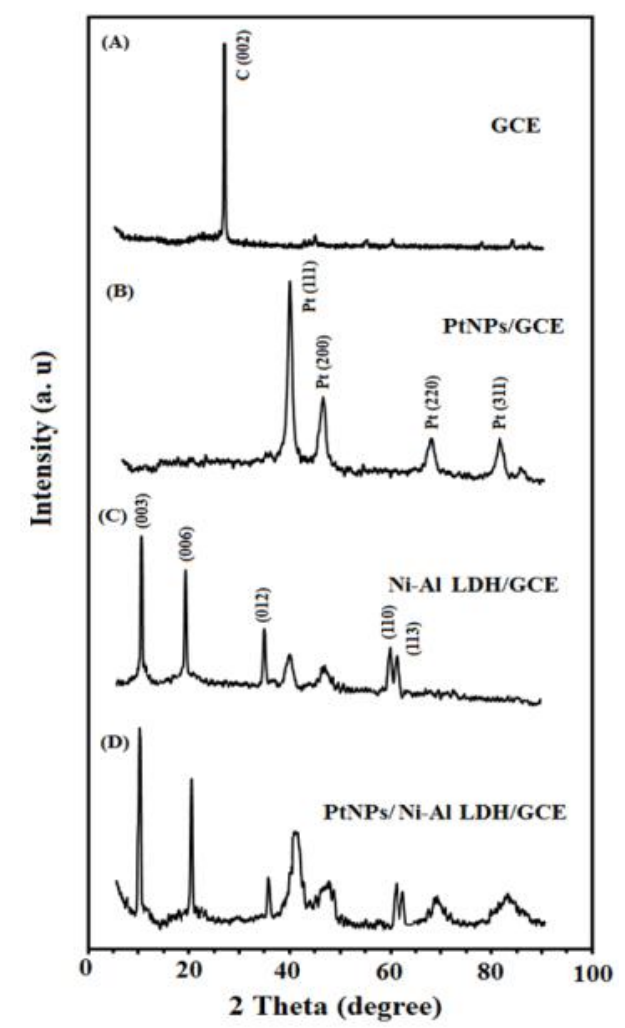

Figure 1. XRD patterns of the GCE (A), PtNPs/GCE (B), Ni-Al LDH/GCE (C) and PtNPs/Ni-Al LDH/GCE (D) 
respectively [54]. Figure $1 \mathrm{C}$ presents the XRD pattern and the characteristic reflections of the $\mathrm{Ni}-\mathrm{Al} \mathrm{LDH} / \mathrm{GCE}$ structure with a series of sharp and intense lines corresponding to structure of $\mathrm{Ni}-\mathrm{Al} \mathrm{LDH}$, four peaks appeared at $2 \theta=$ $10.02^{\circ}, 19.86^{\circ}, 34.52^{\circ}$ and $60.73^{\circ}$, corresponding to the (003), (006), (012), and (110) diffraction planes $[53,55,56]$. The series of intense basal reflections for the $\mathrm{Ni}-\mathrm{Al} \mathrm{LDH} / \mathrm{GCE}$ indicate that LDH film was successfully electrodeposited on GCE surface. All reflections can be indexed as those typical of a hydrotalcite-like LDH family (JCPDS: 38-0487), which also establishes the purity of the $\mathrm{Ni}-\mathrm{Al} \mathrm{LDH}$ obtained from the electrodeposition procedure [44]. The XRD pattern of PtNPs/Ni-Al LDH/GCE (Figure 1D) shows reflections due to both the $\mathrm{Ni}-\mathrm{Al}$ LDH and PtNPs. After electrodeposition of the PtNPs on/in the Ni-Al LDH film at the surface of $\mathrm{GCE}$ and construction of $\mathrm{PtNPs} / \mathrm{Ni}-\mathrm{Al}$ $\mathrm{LDH} / \mathrm{GCE}$, the new series of basic reflections indicate that the PtNPs were successfully electrodeposited on/in the Ni-Al LDH film.

The surface morphology of the Ni-Al LDH/GCE, PtNPs/GCE and PtNPs/Ni-Al LDH/GCE was examined by SEM. SEM images of these materials are shown in Figure 2 (A-C). SEM image of Ni-Al LDH/GCE (Figure 2A) shows an aggregate that consists of crystallites were collected as small spherical particles, and the surface coverage is almost uniform without any holes and deficiencies. Figure $2 \mathrm{~B}$ revealed that the PtNPs are homogeneously distributed on the GCE. While after electrodeposition of the PtNPs on the surface of Ni-Al LDH/GCE, the underlying $\mathrm{Ni}-\mathrm{Al} \mathrm{LDH}$ film was coated by cauliflower-like PtNPs (Figure 2C) which could greatly increase the surface area and improve the catalytic performance. The EDX measurements were used to analysis the surface composition of the electrosynthesized composite and other materials. The EDX spectrums of these
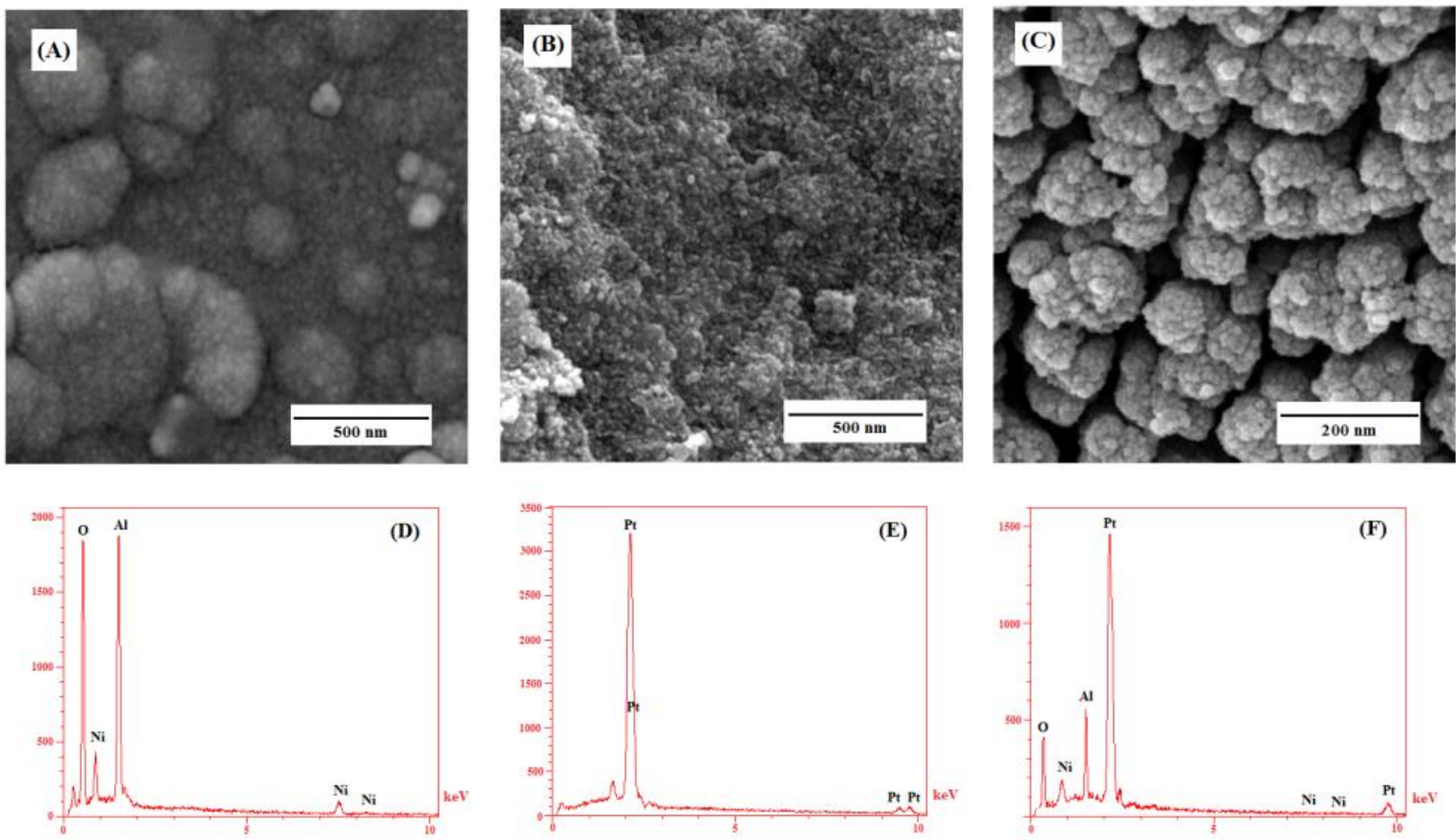

Figure 2. SEM images of the Ni-Al LDH/GCE (Electro deposition Time: 300 s) (A), PtNPs/GCE (Electro deposition Time: $660 \mathrm{~s}$ ) (B) and PtNPs/Ni-Al LDH/GCE (C). EDX spectrums of the Ni-Al LDH/GCE (D), PtNPs/GCE (E) and PtNPs/Ni-Al LDH/GCE (F)

Table 1. Surface chemical composition of modifiers in the present work

\begin{tabular}{cccc}
\hline Modifier & Atoms & Mass content (\%) & Atomic content (\%) \\
\hline PtNPs/Ni-Al LDH & Pt: Ni: Al & $15.07: 11.32: 73.61$ & $2.58: 6.43: 90.99$ \\
Ni-Al LDH & Ni: $\mathrm{Al}$ & $10.46: 89.54$ & $5.10: 94.90$ \\
\hline
\end{tabular}


materials are shown in Figure 2 (D-F). The presence of $\mathrm{Ni}, \mathrm{Al}$ and $\mathrm{O}$ elements was verified in the EDX spectra of $\mathrm{Ni}-\mathrm{Al} \mathrm{LDH} / \mathrm{GCE}$ (Figure 2D), also the presence of only $\mathrm{Pt}$ element (Figure 2E) and $\mathrm{Ni}, \mathrm{Al}, \mathrm{O}$ and $\mathrm{Pt}$ elements (Figure 2F) was verified in the EDX spectrums of PtNPs/GCE and PtNPs/Ni-Al LDH/GCE, respectively. Therefore, the presence of PtNPs in the Ni-Al LDH film is further confirmed from the EDX spectrum. The atomic compositions obtained from EDX analysis for the decorated PtNPs/Ni-Al LDH and Ni-Al LDH/GCE catalysts are shown in Table 1 confirming the presence of $\mathrm{Pt}, \mathrm{Ni}$ and $\mathrm{Al}$ on the GCE surface.

For electrochemical characterization of the PtNPs/Ni-Al LDH/GCE and Ni-Al LDH/GCE, their electrochemical behaviors were investigated by cyclic voltammetry. Figure 3 shows the cyclic voltammograms (CVs) of the PtNPs/Ni-Al LDH and Ni-Al LDH/GCE in 0.5 $\mathrm{M} \mathrm{NaOH}$ solution. Both electrodes show the CVs with a pair of redox peaks between $0.2 \mathrm{~V}$ to $0.5 \mathrm{~V}$, which can be attributed to the quasireversible one electron transfer of $\mathrm{Ni}$ (III)/Ni(II) in this condition, suggesting that the $\mathrm{Ni}-\mathrm{Al}$ $\mathrm{LDH}$ was successfully electrofabricated on the surface of GCE [55]. As reported in the literatures [52] for a Ni-Al LDH, the redox process in basic medium can be represented by the following reaction:

\section{$\mathrm{LDH}-\mathrm{Ni}(\mathrm{II}) / \mathrm{GCE}+\mathrm{OH}_{\text {sol }} \rightarrow \mathrm{LDH}(\mathrm{OH})-\mathrm{Ni}(\mathrm{III}) / \mathrm{GCE}+\mathrm{e}^{-}$}

The charge transport inside the electrode material, Ni-Al LDH film, is due to a mixed mechanism involving an "electron hopping" along the $\mathrm{Ni}-\mathrm{Al} \mathrm{LDH}$ layers, and migration of



Figure 3. CVs of the $\mathrm{Ni}-\mathrm{Al} \mathrm{LDH} / \mathrm{GCE}$ and PtNPs/Ni-Al LDH/GCE in 0.5 M NaOH electrolyte at room temperature and at scan rate of 50 $\mathrm{mV} \mathrm{s}^{-1}$
$\mathrm{OH}^{-}$ions from the solution into the interlayers to compensate the positive extra-charge in the applied anodic potential [52].

On the other hand, a 2-fold enhancement in the anodic peak current density of $\mathrm{Ni}$ (III)/Ni(II) and about $55 \mathrm{mV}$ diminution in the anodic and cathodic peak potentials were achieved by coating and doping the PtNPs on/in Ni-Al LDH film at the surface of GCE. The enhancement in the anodic peak current density of $\mathrm{Ni}$ (III)/Ni(II) couple and diminution of the anodic and cathodic peak potentials in the $\mathrm{PtNPs} / \mathrm{Ni}-\mathrm{Al}$ LDH/GCE can be attributed to increasing the conductivity of the PtNPs/Ni-Al LDH composite with respect to undopted $\mathrm{Ni}-\mathrm{Al} \mathrm{LDH}$ and also catalysis effects of the dopted PtNPs in the vicinity $\mathrm{Ni}(\mathrm{III}) / \mathrm{Ni}(\mathrm{II})$ couples.

\subsection{Electrocatalytic characterization}

The purpose of the present study was to fabricate a catalyst for the electrocatalytic oxidation of methanol in alkaline media. Therefore, we have prepared the PtNPs/Ni-Al LDH/GCE and $\mathrm{Ni}-\mathrm{Al} \mathrm{LDH/GCE}$ where the both of them have almost the same number of electroactive $\mathrm{Ni}$ centers, which have electrocatalytic activity toward methanol oxidation, by controlling the deposition time in the first step of catalyst preparation. On the other hand, in the PtNPs/Ni-Al LDH/GCE in addition to Ni centers, the PtNPs with special electrocatalytic properties toward this fuel, methanol, were electrodeposited in the second step in order to achieve better results. Therefore, in the following, electrocatalytic characterizations of these

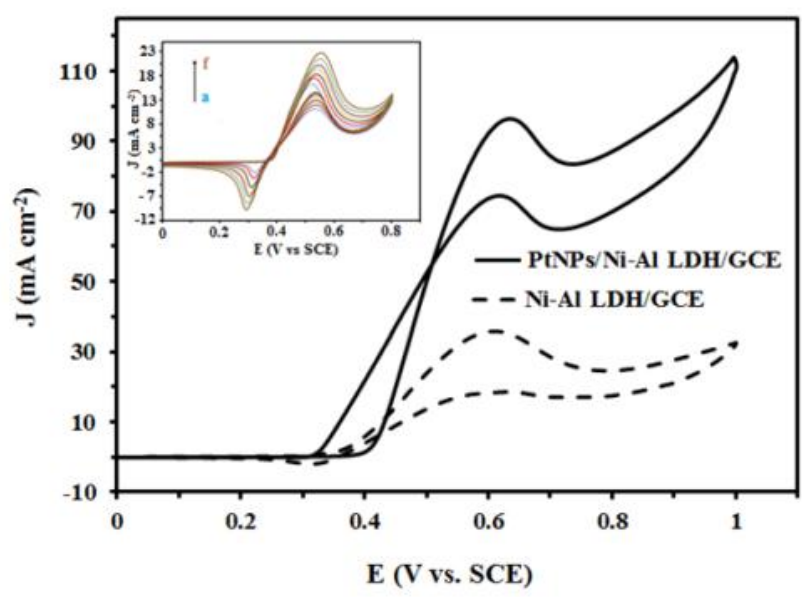

Figure 4. $\mathrm{CVs}$ of the $\mathrm{Ni}-\mathrm{Al} \mathrm{LDH} / \mathrm{GCE}$ and $\mathrm{PtNPs} / \mathrm{Ni}-\mathrm{Al} \mathrm{LDH} / \mathrm{GCE}$ in $0.5 \mathrm{M} \mathrm{NaOH}+0.25$ $\mathrm{M}$ methanol at scan rate of $50 \mathrm{mV} \mathrm{s}^{-1}$. Inset is $\mathrm{CVs}$ of PtNPs/Ni-Al LDH/GCE in 0.5 M NaOH $+0.1 \mathrm{M}$ methanol at different scan rates (30, 50, 90, 130, 150, 200 and $250 \mathrm{mV} \mathrm{s}^{-1}$ ) 
catalysts were tested as the anodic catalysts for methanol oxidation in alkaline media. The electrocatalytic characterizations of the PtNPs/Ni/Al-LDH/GCE and Ni/Al-LDH/GCE toward methanol oxidation were evaluated in details by cyclic voltammetry, chronoamperometry, and chronopotentiometry methods and the obtained CVs in alkaline media were shown in Figure 4. As can be seen, both CV curves show a similar methanol oxidation current peak in the forward scan and an oxidation peak in the backward scan corresponding to the removal of the residual carbonaceous species formed during methanol oxidation in the forward scan [8,53]. Meanwhile, the anodic peak appeared during the forward scan reappeared almost at the same potential during the backward scan [55]. As we know, the magnitude of the peak current density in the forward scan indicates the electrocatalytic activity of the electrocatalyst for methanol oxidation. From Figure 4, can see that the methanol oxidation current in the forward scan is significantly higher on the PtNPs/Ni/Al-LDH/GCE (97 $\left.\mathrm{mA} / \mathrm{cm}^{2}\right)$ than on the $\mathrm{Ni}-\mathrm{Al} \mathrm{LDH} / \mathrm{GCE}$ (37 $\mathrm{mA} / \mathrm{cm}^{2}$ ) and also on the PtNPs/GCE (50.5 $\mathrm{mA} / \mathrm{cm}^{2}$ ), indicating that there is a contributory effect between PtNPs and Ni-Al LDH in the obtained nanocomposite and enhances their performance in methanol electrooxidation [43,49]. This result approves that the $\mathrm{PtNPs} / \mathrm{Ni}-\mathrm{Al}$ LDH/GCE has a better electrocatalytic activity for methanol oxidation in alkaline media. The possible reason for this trend can be summarized as follows: (1) synergistic effect between PtNPs and Ni-Al LDH and its promoting properties; (2) content increase of metallic state of the PtNPs in the PtNPs/Ni-Al LDH/GCE nanocomposite, which is well known that the more content of metallic state in catalysts, the better catalytic performance; (3) increasing the conductivity of the PtNPs/Ni-Al LDH nanocomposite with respect to undopted $\mathrm{Ni}-\mathrm{Al} \mathrm{LDH}$; and finally (4) as a hydroxide ion conductor, $\mathrm{Ni}-\mathrm{Al}$ $\mathrm{LDH}$ could deliver $\mathrm{OH}^{-}$and increase the concentration of $\mathrm{OH}^{-}$around the $\mathrm{PtNPs}$ and bifunctional effect between the $\mathrm{OH}^{-}$and PtNPs similar with the commonly accepted bifunctional effect between $\mathrm{Pt}$ and $\mathrm{Ru}[57,58]$ in the case of Pt-Ru electrocatalyst [59] to remove the intermediate carbonaceous species and contribute to the low poisoning.

It should be noted that, under a low concentration of methanol $(0.1 \mathrm{M})$, the anodic peak current in the forward scan for methanol oxidation and cathodic peak current of $\mathrm{Ni}$ (III)/Ni(II) couple in the backward scan presented in the CV gram (inset of Figure 4) due to unmasking the cathodic current of $\mathrm{Ni}(\mathrm{III}) / \mathrm{Ni}(\mathrm{II})$ couple by the methanol oxidation peak [55].

In this section, the effects of some parameters on the electrocatalytic activity of the PtNPs/Ni-Al LDH/GCE and Ni-Al LDH/GCE were studied. Firstly, the effect of electrodeposition times in the both steps of electrocatalyst preparation; Ni-Al LDH deposition on the GCE for preparation of $\mathrm{Ni}-\mathrm{Al} \mathrm{LDH} / \mathrm{GCE}$ and PtNPs deposition on/in the Ni-Al LDH film for the preparation of $\mathrm{PtNP} / \mathrm{Ni}-\mathrm{Al} \mathrm{LDH} / \mathrm{GCE}$, on the anodic current density of methanol oxidation reaction in the forward scan was studied. Figure 5 shows the value of the anodic current density for methanol oxidation on the PtNPs/Ni-Al LDH/GCE (A) and Ni-Al LDH/GCE (B) after 60, 180, 300, 420, 540, 660, 780 and $900 \mathrm{~s}$ for the Ni-Al LDH electrodeposition and 300, 420, 540, 660, 780 and $900 \mathrm{~s}$ for the PtNPs electrodeposition, respectively.
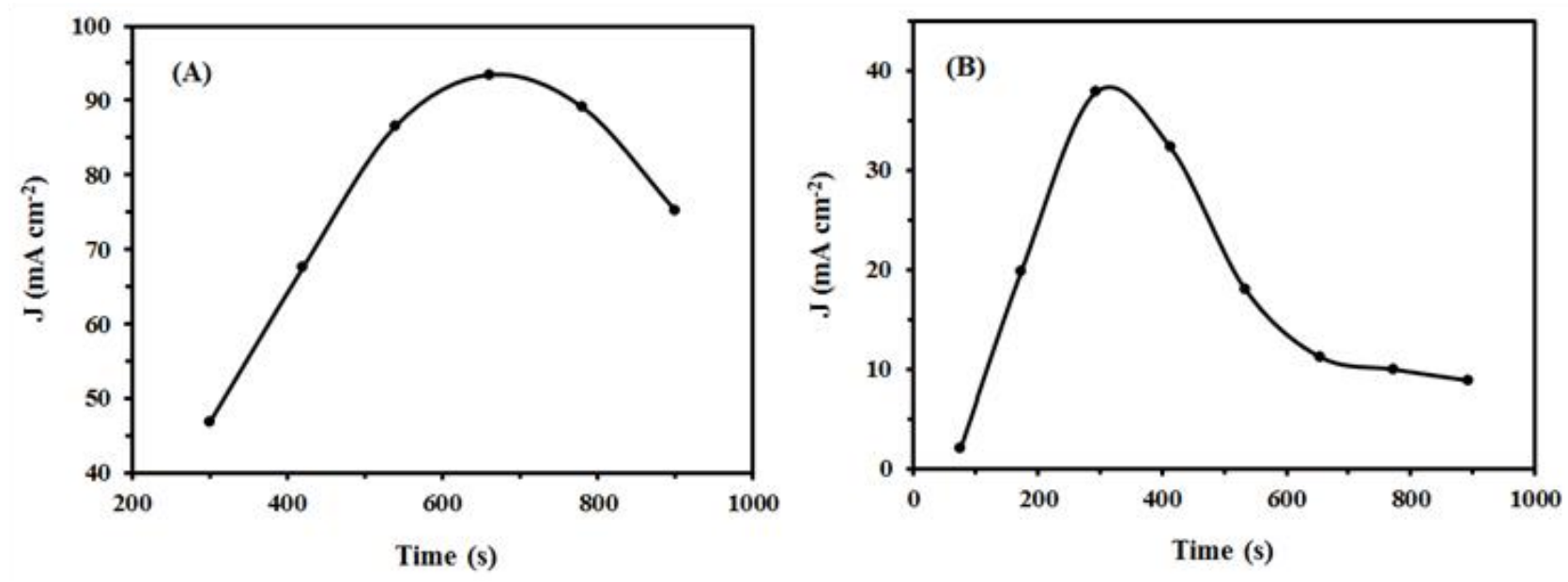

Figure 5. The plots of the anodic peak current density in the forward scan versus time (s) for electro deposition of PtNPs (A) and electro deposition of Ni-Al LDH (B) 
These experiments were repeated for 3 times and the same results were obtained (mean of data were shown). The anodic current density for methanol oxidation increased with increasing the electrodeposition time up to $300 \mathrm{~s}$ and $660 \mathrm{~s}$ respectively for $\mathrm{Ni} / \mathrm{Al}-\mathrm{LDH}$ and PtNPs electrodeposition. Increasing of anodic current density is due to increase in the real surface area of the electrocatalyst. With further increase in the electrodeposition times, the methanol oxidation current density started to decrease [41]. Possible explanation could be that the decreasing the real surface area of the electrocatalyst due to the agglomeration of PtNPs or decreasing the conductivity of the NiAl LDH film by increasing the thickness $[41,55]$.

In order to investigate the kinetic charac-


Figure 6. (A) $\mathrm{CVs}$ of the PtNPs/Ni-Al LDH/GCE in $0.5 \mathrm{M} \mathrm{NaOH}+0.25 \mathrm{M}$ methanol at different scan rates $\left(10,20,40,60,80\right.$ and $\left.100 \mathrm{mV} \mathrm{s}^{-1}\right)$. (B) Plot of the anodic peak current density versus the square root of scan rates. The inset is $E(V$ vs. $S C E)$ versus the $\ln v\left(\mathrm{mV} \mathrm{s}^{-1}\right)$

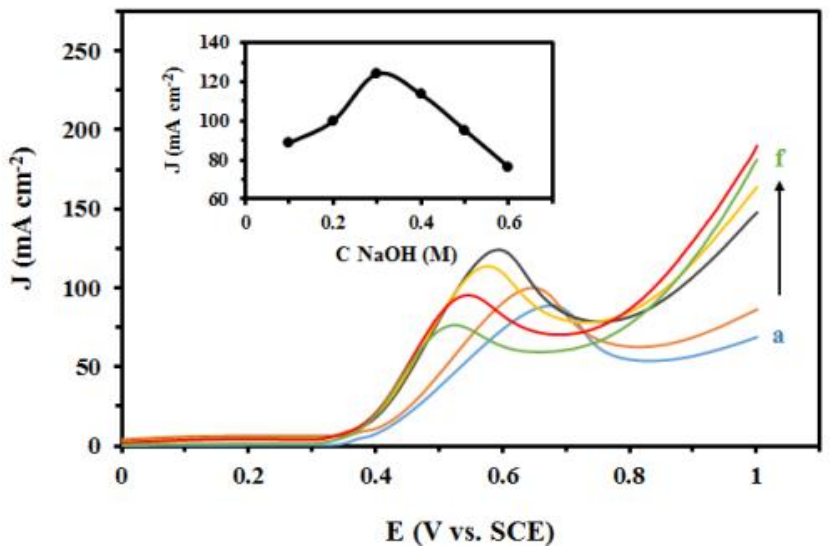

Figure 7. CVs of the PtNPs/Ni-Al LDH/GCE for $0.25 \mathrm{M}$ methanol at a scan rate of $50 \mathrm{mV} \mathrm{s}^{-1}$ at various $\mathrm{NaOH}$ concentrations ( 0.1 to $0.6 \mathrm{M}$ from a to $\mathrm{f}$ ). The inset is the anodic peak current density at various electrolyte concentrations terization of methanol oxidation on the PtNPs/Ni-Al LDH/GCE electrocatalyst, we looked into the effect of scan rate on the anodic current density of methanol oxidation in the forward scan. The effect of scan rate on the electrooxidation of $0.25 \mathrm{M}$ methanol in 0.5 $\mathrm{M} \mathrm{NaOH}$ solution is shown in Figure 6 (A). The results clearly exhibit that the anodic peak current density associated to methanol electrooxidation increases linearly with the increase of the scan rate. The relation between the peak current density obtained from forward scan and $v^{1 / 2}$ is shown in Figure 6 (B). There is a linear relationship with a high correlation coefficient $\left(\mathrm{R}^{2}>0.97\right)$ between peak current density and square root of scan rate, implying that the methanol oxidation is typically under diffusion control [57-60]. Moreover, 
the oxidation peak potential in the forward scan $\left(E_{f}\right)$ shifts positively with increasing scan rate $(v)$. A linear relationship can be obtained between $E_{f}$ and $\ln (v)$, as shown in the inset of Figure 6 (B). This indicates that the oxidation of methanol oxidation on the PtNPs/Ni-Al LDH/GCE electrocatalyst is completely an irreversible process $[8,58]$.

The role of $\mathrm{OH}^{-}$ion in the oxidation of methanol has been discussed at various $\mathrm{Ni}$ containing species modified electrodes [38$41,53,55,60-62]$. The effect of $\mathrm{NaOH}$ concentration on the methanol oxidation at the $\mathrm{PtNP}_{\mathrm{s}} / \mathrm{Ni}-\mathrm{Al} \mathrm{LDH} / \mathrm{GCE}$ was investigated. The $\mathrm{CVs}$ of PtNPs/Ni-Al LDH/GCE were recorded in $0.25 \mathrm{M}$ methanol solution in the presence of various concentrations of $\mathrm{NaOH}$ ranging from 0.1 to $0.6 \mathrm{M}$ at a scan rate of $50 \mathrm{mV} \mathrm{s}^{-1}$. Figure 7 shows the effect of $\mathrm{NaOH}$ concentration on the oxidation of methanol (only forward scans were shown). It can be seen that with an increase in $\mathrm{OH}^{-}$concentration the peak potential shifts toward more negative values and the anodic peak current density of methanol oxidation increase by increasing the $\mathrm{NaOH}$ concentration up to $0.3 \mathrm{M}$ and then decrease at concentration higher than $0.3 \mathrm{M}$. These results indicate that the $\mathrm{OH}^{-}$ion participates in the oxidation of methanol and may be adverse to the oxidation of methanol for the competitive adsorption on the active sites to methanol. At low $\mathrm{OH}^{-}$concentration $(<0.3 \mathrm{M})$, the peak potential shifts toward more negative values with an increase in $\mathrm{OH}^{-}$concentration, because as mentioned already the anodic current density in forward scan mainly comes from the oxidation of methanol and increasing the concentration of $\mathrm{OH}^{-}$around the PtNPs increase the bifunctional effect between the $\mathrm{OH}^{-}$and PtNPs [5759] to remove the intermediate carbonaceous species and contribute to the low poisoning. On the other hand, in more alkaline electrolytes $(>>0.3 \mathrm{M})$ the adsorption of $\mathrm{OH}-$ prevents the methanol adsorption on the electrocatalyst sites and so the reaction rate of methanol oxidation decreases [63].

Figure 8 shows the effect of methanol concentrations on the electrooxidation current density of this fuel at the PtNPs/Ni-Al LDH/GCE in $0.5 \mathrm{M} \mathrm{NaOH}$ solution. It can be clearly observed that increasing the methanol concentration up to $0.6 \mathrm{M}$ increases the anodic current density and, there is not any significant increase in the current density of methanol oxidation in methanol concentrations higher than $0.6 \mathrm{M}$. This effect might be due to the saturation of active sites on the surface of the electrode by methanol molecules and also contami- nation of the electrocatalyst surface which is mainly arisen from the $\mathrm{CO}_{\text {ads }}$ intermediate during the methanol oxidation [64-66]. When the fuel concentration increases, the peak potential of the anodic peak in the forward and backward scan (inset of Figure 8 for forward scan) were shifted to high positive values. These may be occur because of this probably reason: the poisoning rate of the PtNPs sites increases with increasing the fuel concentration and the oxidative removal of the strongly adsorbed intermediates would shift to a more positive potential [67]. In accordance with this result, it displays that the concentration value of $0.6 \mathrm{M}$ indicates a critical concentration after which the adsorption of the oxidation products at the PtNPs/Ni-Al LDH/GCE catalyst surface causes the hindrance of further methanol oxidation.

\subsection{Stability characterization}

Long-term structural durability is one of the most essential characteristics for FCs to be accepted as a viable product. Poisoning of the electrocatalysts with intermediate species produced during alcohol oxidation reaction influences their long-term performance. The resistance of the electrocatalysts to $\mathrm{CO}_{\mathrm{ad}}$-poisoning has been evaluated by various stability and durability tests such as repetitive potential cycling, change in the CV profile after many cycles [66-68], potential holding method [69] and potential step method [70]. In this work, to evaluate the long-term stability of $\mathrm{PtNPs} / \mathrm{Ni}-\mathrm{Al}$ LDH/GCE for methanol oxidation, the forward anodic peak current density was followed over 200 successive cycles at a scan rate of $50 \mathrm{mV} \mathrm{s}^{-1}$ in $\mathrm{NaOH}$ solution containing $0.25 \mathrm{M}$ methanol (1 ${ }^{\text {st }}, 25^{\text {th }}$ and $50^{\text {th }}$ cycles was shown in inset of

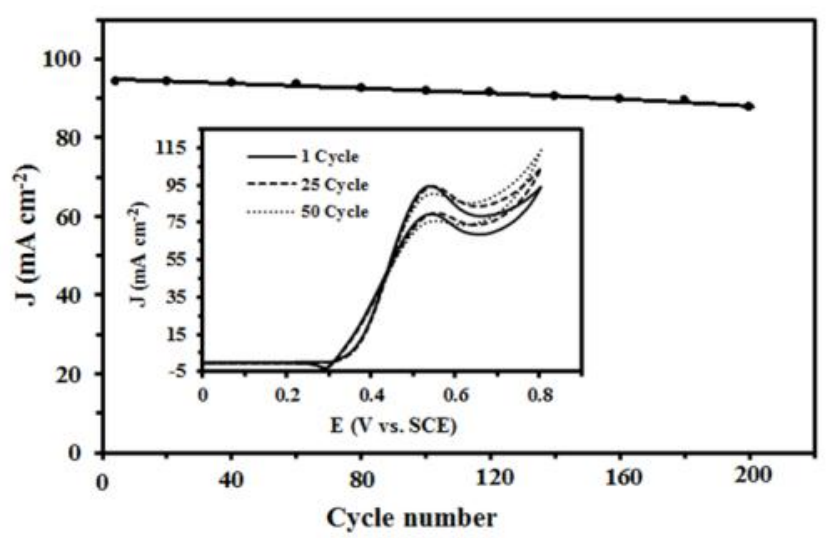

Figure 9. Plot of the anodic peak current density in the forward scan at the PtNPs/Ni-Al LDH/GCE in $0.5 \mathrm{M} \mathrm{NaOH}+0.25 \mathrm{M}$ methanol solution at scan rate of $50 \mathrm{mV} \mathrm{s}^{-1}$ in different scans (Long-term stability). Inset is the CVs of 1,25 and $50^{\text {th }}$ cycles 
Figure 9). The current density of anodic peak in the forward scan versus number of cycles is shown in Figure 9. It can be observed that the peak current density decreases very slowly with the consecutive scans. After 200 cycles, the anodic peak current density remains at $95.41 \%$ of the $1^{\text {st }}$ cycle (the good performing cycle). Ni-Al LDH particles, with the presence of sites and functional groups, may lead to a strong LDH-Pt interaction and resultant resistance of $\mathrm{Pt}$ to poisoning, and therefore enhanced durability [38-41,71]. The loss of the electrocatalytic activity may be related to $\mathrm{Pt}$ nanoparticles aggregation/degradation.

The stability of current generated by the electrocatalysts can be tested by further experiments; chronoamperometric method. Thus, in our following experiments, the stability of the PtNPs/Ni-Al LDH/GCE and Ni-Al LDH/GCE was tested by chronoamperometry. Figure 10 shows the typical chronoamperograms of the PtNPs/Ni-Al LDH/GCE and Ni-Al LDH/GCE in $0.5 \mathrm{M} \mathrm{NaOH}$ and $0.25 \mathrm{M}$ methanol aqueous solution at a fixed potential of $0.65 \mathrm{~V}$ for $2000 \mathrm{~s}$. The superior performance of the $\mathrm{PtNPs} / \mathrm{Ni}-\mathrm{Al}$ $\mathrm{LDH} / \mathrm{GCE}$ with respect to the Ni-Al LDH/GCE is also reflected in the chronoamperometry measurements. The initial sharp rapid decrease at the initial stage in the polarization current density for the Ni-Al LDH/GCE is attributed to the poisoning effect of the intermediate species during the methanol electrooxidation reaction in alkaline medium. However, rapidly decreasing in the current density for PtNPs/Ni-Al LDH/GCE occurs in the first milliseconds but is very much slower than compared with Ni-Al LDH/GCE and subsequently the current density reaches a pseudo steady state [72]. The approximate steady current values af-

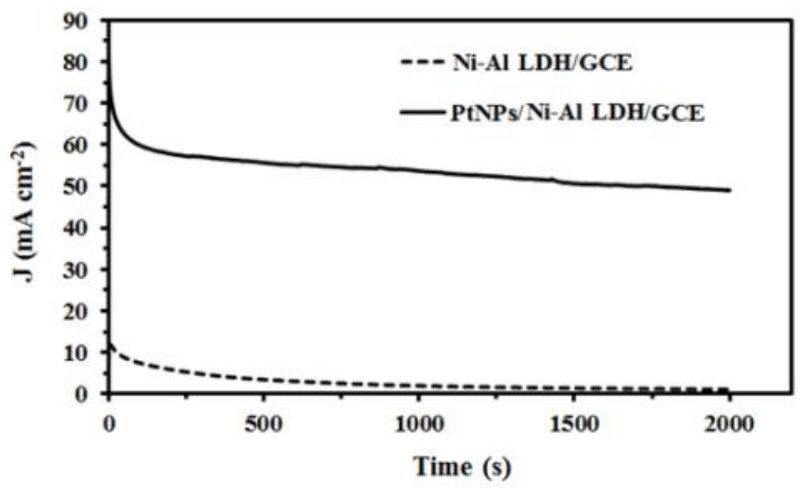

Figure 10. Chronoamperometric curves for the PtNPs/Ni-Al LDH/GCE and Ni-Al LDH/GCE in $0.5 \mathrm{M} \mathrm{NaOH}+0.25 \mathrm{M}$ methanol solution (polarization potential: $0.65 \mathrm{~V}$ ) for $2000 \mathrm{~s}$ ter $10 \mathrm{~s}$ methanol oxidation period were found to be 60.1 and $9.7 \mathrm{~mA} \mathrm{~cm}^{-2}$, respectively on the PtNPs/Ni-Al LDH/GCE and Ni-Al LDH/GCE. The quasi-stable current densities at the end of the test after $2000 \mathrm{~s}$ were 49.7 and $1.6 \mathrm{~mA} \mathrm{~cm}^{-2}$ respectively on the $\mathrm{PtNPs} / \mathrm{Ni}-\mathrm{Al} \mathrm{LDH} / \mathrm{GCE}$ and $\mathrm{Ni}-\mathrm{Al} \mathrm{LDH} / \mathrm{GCE}$. It can be seen from chronoamperometry test that the methanol oxidation on the PtNPs/Ni/Al-LDH/GCE possesses higher initial and limiting current density and this electrocatalyst gave the very higher stable current response, which displays better catalytic activity and stability. These results corroborate our observation from the cyclic voltammetry.

Further performance evaluation test of the PtNPs/Ni-Al LDH/GCE was carried out by chronopotentiometry. Chronopotentiometry is a powerful method to study the poisoningresistance abilities of electrocatalysts for alcohol oxidation. Figure 11 shows the chronopotentiometric curves, measured in $0.5 \mathrm{M} \mathrm{NaOH}$ solution that contains $0.25 \mathrm{M}$ methanol at a current of $95 \mathrm{~mA} \mathrm{~cm}^{-2}$ and $35 \mathrm{~mA} \mathrm{~cm}^{-2}$, respectively for $\mathrm{PtNP} / \mathrm{Ni}-\mathrm{Al} \mathrm{LDH} / \mathrm{GCE}$, and $\mathrm{Ni}-\mathrm{Al}$ LDH/GCE. Theoretically, the electrode potential will increase to a higher value when charged by a positive current based on the electrochemical principle [73]. The markedly different shape of the $V$-t curve strongly indicates that these different electrocatalysts exhibited various electrochemical responses when being charged. It is obvious that the electrode potential of $\mathrm{PtNPs} / \mathrm{Ni}-\mathrm{Al} \mathrm{LDH} / \mathrm{GCE}$ remains the lower value than $\mathrm{Ni}-\mathrm{Al} \mathrm{LDH} / \mathrm{GCE}$. Also, it can be clearly seen from Figure 11 that the potential increased rapidly in the first seconds and the polarization potential gradually increases

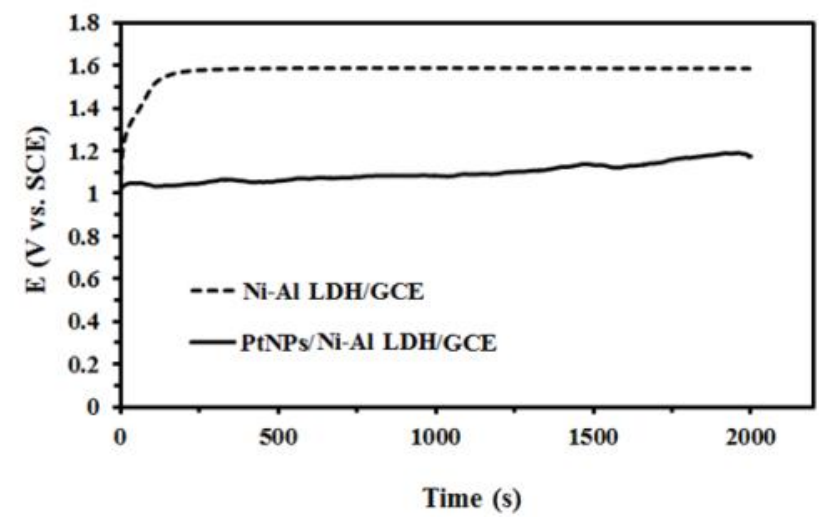

Figure 11. Chronopotentiometric curves for the PtNPs/Ni-Al LDH/GCE and Ni-Al $\mathrm{LDH} / \mathrm{GCE}$ in $0.5 \mathrm{M} \mathrm{NaOH}+0.25 \mathrm{M}$ methanol solution (polarization current: $95 \mathrm{~mA} \mathrm{~cm}^{-2}$ for PtNPs/Ni/Al-LDH/GCE and $35 \mathrm{~mA} \mathrm{~cm}^{-2}$ for $\mathrm{Ni} / \mathrm{Al}-\mathrm{LDH} / \mathrm{GCE}$ ) for $2000 \mathrm{~s}$ 
with time. The over potential of $\mathrm{Ni}-\mathrm{Al}$ $\mathrm{LDH} / \mathrm{GCE}$ is higher than PtNPs/Ni-Al LDH/GCE electrocatalyst; therefore, PtNPs/Ni$\mathrm{Al} \mathrm{LDH/GCE}$ is conducive to lower overpotential of Ni-Al LDH/GCE. A lower overpotential is an indication of better electroactivity, thus PtNPs/Ni-Al LDH/GCE represents the better electroactivity than Ni-Al LDH/GCE [74]. Some reported results confirm that $\mathrm{LDH}$ films have anti-poisoning property, which turns easier any oxidation reaction [41,55,72], and this is more efficient in fuel cells.

\section{Conclusions}

In this study, Ni-Al layered double hydroxides (Ni-Al LDH)-Pt nanoparticles (PtNPs) composite by a facile two-step electrochemical method is electrodeposited on the GCE. After physicochemical characterizations of PtNPs/Ni$\mathrm{Al} \mathrm{LDH/GCE}$, its electrocatalytic and stability characterizations toward methanol oxidation in alkaline media were investigated in detail by cyclic voltammetry, chronoamperometry and chronopotentiometry measurements. PtNPs/NiAl LDH/GCE exhibited higher electrocatalytic activity than PtNPs/GCE and Ni-Al LDH/GCE and also the obtained chronoamperograms indicated that the PtNPs/Ni-Al LDH/GCE has a better stability. Therefore, this work provides an effective method to electrodepositing the PtNPs/Ni-Al LDH on the GCE surfaces to prepare a relatively low-cost nanocomposite that may be used as potential anode material for DMFCs in alkaline media.

\section{Acknowledgement}

The authors gratefully acknowledge the Research Council of Azarbaijan Shahid Madani University for financial support.

\section{References}

[1] Carrette, L., Friedrich, K.A., Stimming, U. (2000). Fuel Cells: Principles, Types, Fuels, and Application. Chem. Phys. Chem., 4: 162193.

[2] Steele, B.C.H., Heinzel, A. (2001). Materials for Fuel-cell Technologies. Nature, 414: 345352.

[3] Wang, Y., Chen, K.S., Mishler, J., Cho, S.C., Adroher, X.C. (2011). A Review of Polymer Electrolyte Membrane Fuel Cells: Technology, Applications, and Needs on Fundamental Research. Appl. Energ., 88: 981-1007.

[4] Sharaf, O.Z., Orhan, M.F. (2014). An Overview of Fuel Cell Technology: Fundamentals and Applications. Renew. Sustain. Energ. Rev., 32: 810-853,

[5] Pei, P., Chen, H. (2014). Main Factors Affecting the Lifetime of Proton Exchange Membrane Fuel Cells in Vehicle Applications: A Review. Appl. Energ., 125: 60-75.

[6] Badwal, S.P.S., Giddey, S., Kulkarni, A., Goel, J., Basu, S. (2015). Direct Ethanol Fuel Cells for Transport and Stationary Applications - A Comprehensive Review. Appl. Energ., 145: 80-103.

[7] Lamy, C., Lima, A., LeRhun, V., Delime, F., Coutanceau, C., Léger, J.M. (2002). Recent Advances in the Development of Direct Alcohol Fuel Cells (DAFC). J. Power Sources, 105: 283-296.

[8] Lamy, C., Belgsir, E.M., Léger, J.M.(2001). Electrocatalytic Oxidation of Aliphatic Alcohols: Application to the Direct Alcohol Fuel Cell (DAFC). J. Appl. Electrochem., 31:799809.

[9] Merle, G., Wessling, M., Nijmeijer, K. (2011). Anion Exchange Membranes for Alkaline Fuel Cells: A Review. J. Membrane. Sci., 377: 1-35.

[10] Antolini, E., Gonzalez, E.R. (2010). Alkaline Direct Alcohol Fuel Cells. J. Power Sources, 195: 3431-3450.

[11] Yu, E.H., Krewer, U., Scott, K. (2010). Principles and Materials Aspects of Direct Alkaline Alcohol Fuel Cells. Energies, 3: 1499-1528.

[12] Verma, A., Basu, S. (2005). Direct Use of Alcohols and Sodium Borohydride as Fuel in an Alkaline Fuel Cell. J. Power Sources, 145: 282-285.

[13] Matsuoka, K., Iriyama, Y., Abe, T., Matsuoka, M., Ogumi, Z. (2005). Alkaline Direct Alcohol Fuel Cells using an Anion Exchange Membrane. J. Power Sources, 150: 27-31.

[14] Sheikh, A.M., Abd-Alftah, K.E.A., Malfatti, C.F. (2014). On Reviewing the Catalyst Materials for Direct Alcohol Fuel Cells (DAFCs). Journal of Multidisciplinary Engineering Science and Technology (JMEST), 1: 1-10.

[15] Chen, Y., Bellini, M., Bevilacqua, M., Fornasiero, P., Lavacchi, A., Miller, H.A., Wang, L., Vizza, F. (2015). Direct Alcohol Fuel Cells: Toward the Power Densities of Hydrogen-Fed Proton Exchange Membrane Fuel Cells. Chem. Sus. Chem., 8: 524-533.

[16] Chen, Y., Zhuang, L., Juntao, L.U. (2007). Non-Pt Anode Catalysts for Alkaline Direct Alcohol Fuel Cells. Chin. J. Catal., 28: 870874.

[17] Kamaruddin, M.Z.F., Kamarudin, S.K., Daud, W.R.W., Masdar, M.S. (2013). An 
Overview of Fuel Management in Direct Methanol Fuel Cells. Renew Sust. Energ. Rev., 24: 557-565.

[18] Deng, H., Chen, J., Jiao, K., Huang, X. (2014). An Analytical Model for Alkaline Membrane Direct Methanol Fuel Cell. Int. J. Heat Mass Transfer, 74: 376-390.

[19] Velu, S., Suzuki, K., Osaki, T. (2000). A Comparative Study of Reactions of Methanol over Catalysts Derived from NiAl- and CoAllayered Double Hydroxides and their Sncontaining Analogues. Catal. Lett., 69: 43-50.

[20] Centi, G., Perathoner, S. (2008). Catalysis by Layered Materials: A Review. Micropor. Mesopor. Mater., 107: 3-15.

[21] Morioka, H., Tagaya, H., Karasu, M., Kadokawa, J., Chiba, K. (1995). Preparation of New Useful Materials by Surface Modification of Inorganic Layered Compound. J. Solid State Chem., 117: 337-342.

[22] Suib, S.L. (1996). Synthesis, Characterization and Catalysis with Microporous Ferrierites, Octahedral Molecular Sieves, and Layered Materials. Studies in Surface Science and Catalysis, 102: 47-74.

[23] Chen, X., Mi, F., Zhang, H., Zhang, H. (2012). Facile Synthesis of a Novel Magnetic Coreshell Hierarchical Composite Submicrospheres $\mathrm{Fe}_{3} \mathrm{O}_{4} @ \mathrm{CuNiAl}-\mathrm{LDH}$ under Ambient Conditions. Mater. Lett., 69: 48-51.

[24] Li, C., Wei, M., Evans, D.G., Duan, X. (2015). Recent Advances for Layered Double Hydroxides (LDHs) Materials as Catalysts Applied in Green Aqueous Media. Catal. Today, 247: 163-169.

[25] Shan, D., Cosnier, S., Mousty, C. (2003). Layered Double Hydroxides: An Attractive Material for Electrochemical Biosensor Design. Anal. Chem., 75: 3872-3879.

[26] Xu, Z.P., Braterman, P.S. (2010). Synthesis, Structure and Morphology of Organic Layered Double Hydroxide (LDH) Hybrids: Comparison between Aliphatic Anions and their Oxygenated Analogs. Appl. Clay. Sci., 48: 235242.

[27] Carrado, K.A., Kostapapas, A. (1988). Layered Double Hydroxides (LDHs). Solid State Ionics, 26: 77-86.

[28] Xu, Z.P., Zhang, J., Adebajo, M.O., Zhang, H., Zhou, C. (2011). Catalytic Applications of Layered Double Hydroxides and Derivatives. Appl. Clay Sci., 53: 139-150.

[29] Huang, L., Zhou, J., Hsu, A.T., Chen, R. (2013). Catalytic Partial Oxidation of nButanol for Hydrogen Production over LDHDerived Ni-based Catalysts. Int. J. Hydrogen Energy, 38: 14550-14558.
[30] Karim-Nezhad, G., Pashazadeh, S., Pashazadeh, A. (2012). Electrocatalytic Oxidation of Methanol and Ethanol by Carbon Ceramic Electrode Modified with Ni/Al LDH Nanoparticles. Chin. J. Catal., 33: 1809-1816.

[31] Wang, J., Song, Y., Li, Z., Liu, Q., Zhou, J., Jing, X., Zhang, M., Jiang, Z. (2010). In Situ $\mathrm{Ni} / \mathrm{Al}$ Layered Double Hydroxide and Its Electrochemical Capacitance Performance. Energy Fuel, 24: 6463-6467.

[32] Li, M., Cheng, J.P., Fang, J.H., Yang, Y., Liu, F., Zhang, X.B. (2014). NiAl-layered Double Hydroxide/Reduced Graphene Oxide Composite: Microwave-assisted Synthesis and Supercapacitive Properties. Electrochim. Acta, 134: 309-318.

[33] Ju, J., Bai, J., Bo, X., Guo, L. (2012). Nonenzymatic Acetylcholine Sensor Based on Ni$\mathrm{Al}$ Layered Double Hydroxides/ordered Mesoporous Carbon. Electrochim. Acta, 78: 569-575.

[34] Yin, H., Cui, L., Ai, S., Fan, H., Zhu, L. (2010). Electrochemical Determination of Bisphenol A at $\mathrm{Mg}-\mathrm{Al}-\mathrm{CO}_{3}$ Layered Double Hydroxide Modified Glassy Carbon Electrode. Electrochim. Acta, 55: 603-610.

[35] Cui, L., Meng, X., Xu, M., Shang, K., Ai, S., Liu, Y. (2011). Electro-oxidation Nitrite Based on Copper Calcined Layered Double Hydroxide and Gold Nanoparticles Modified Glassy Carbon Electrode. Electrochim. Acta, 56: 9769-9774.

[36] Zou, X., Goswami, A., Asefa, T. (2013). Efficient Noble Metal-Free (Electro) Catalysis of Water and Alcohol Oxidations by Zinc-Cobalt Layered Double Hydroxide. J. Am. Chem. Soc., 135: 17242-17245.

[37] Nityashree, N., Menezes, P. (2013). Mg/Al Layered Double Hydroxide-Pt Nanoparticle Composite by Delamination-restacking Route. Appl. Nanosci., 3: 321-327.

[38] Karim-Nezhad, G., Pashazadeh, S., Pashazadeh, A. (2012). Ni/Al LDH Nanoparticles Modified Carbon Paste Electrode: Application to Electro-Catalytic Oxidation of Methanol. Anal. Bioanal. Electrochem., 4: 399-416.

[39] Zhang, L., Li, F. (2010). Synthesis of Carbon Nanotubes/metal Oxide Composites over Layered Double Hydroxides and Application in Electrooxidation of Ethanol. Appl. Clay Sci., 50: 64-72.

[40] Kubo, D., Tadanaga, K., Hayashi, A., Tatsumisago, M. (2013). Improvement of Electrochemical Performance in Alkaline Fuel Cell by Hydroxide Ion Conducting $\mathrm{Ni}$-Al Layered Double Hydroxide. J. Power Sources, 222: 493-497. 
[41] Wang, Y., Zhang, D., Tang, M., Xu, S., Li, M. (2010). Electrocatalysis of Gold Nanoparticles/layered Double Hydroxides Nanocomposites toward Methanol Electro-oxidation in Alkaline Medium. Electrochim. Acta, 55: 4045-4049.

[42] Pournaghi-Azar, M.H., Habibi, B. (2007). Nickel Hexacyanoferrate Film Immobilized on the Aluminum Electrode as an Inorganic Matrix for Dispersion of Platinum and some Platinum Alloys Particles for Electrocatalytic Oxidation of Methanol. J. Electroanal. Chem., 605: 136-144.

[43] Therese, G.H.A., Kamath, P.V. (2000). Electrochemical Synthesis of Metal Oxides and Hydroxides. Chem. Mater. 12: 1195-1204.

[44] Scavetta, E., Ballarin, B., Gazzano, M., Tonelli, D. (2009). Electrochemical Behaviour of Thin Films of Co/Al Layered Double Hydroxide Prepared by Electrodeposition. Electrochim. Acta, 54: 1027-1033.

[45] Wang, Y., Rui, Y., Li, F., Li, M. (2014). Electrodeposition of Nickel Hexacyanoferrate/layered Double Hydroxide Hybrid Film on the Gold Electrode and its Application in the Electroanalysis of Ascorbic Acid. Electrochim. Acta, 117: 398-404.

[46] Mignani, A., Ballarin, B., Giorgetti, M., Scavetta, E., Tonelli, D., Boanini, E., Prevot, V., Mousty, C., Iadecola, A. (2013). Heterostructure of $\mathrm{Au}$ Nanoparticles-NiAl Layered Double Hydroxide: Electrosynthesis, Characterization, and Electrocatalytic Properties. J. Phys. Chem. C, 117: 16221-16230.

[47] Scavetta, E., Stipa, S., Tonelli, D. (2007). Electrodeposition of a Nickel-based Hydrotalcite on Pt Nanoparticles for Ethanol and Glucose Sensing. Electrochem. Commun., 9: 28382842 .

[48] Guo, X., Zhang, F., Evans, D.G., Duan, X. (2010). Layered Double Hydroxide Films: Synthesis, Properties and Applications. Chem. Commun., 46: 5197-5210.

[49] Habibi, B., Delnavaz, N. (2010). Electrocatalytic Oxidation of Formic Acid and Formaldehyde on Platinum Nanoparticles Decorated Carbon-ceramic Substrate. Int. J. Hydrogen Energy, 35: 8831-8840.

[50] Scavetta, E., Ballarin, B., Giorgetti, M., Carpani, I., Cogo, F., Tonelli, D. (2004). Electrodes Modified by One-Step Electrosynthesis of $\mathrm{Ni} / \mathrm{Al}-\mathrm{NO}_{3}$ Double Layered Hydroxide. $J$. New Mater. Electrochem. Syst., 7: 43-50.

[51] Indira, L., Kamath, P.V. (1994). Electrosynthesis of Layered Double Hydroxides of Nickel with Trivalent Cations. J. Mater. Chem., 4: 1487-1490.
[52] Scavetta, E., Mignani, A., Prandstraller, D., Tonelli, D. (2007). Electrosynthesis of Thin Films of Ni, Al Hydrotalcite Like Compounds. Chem. Mater., 19: 4523-4529.

[53] Wang, Y., Ji, H., Peng, W., Liu, L., Gao, F., Li, M. (2012). Gold Nanoparticle-coated Ni/Al Layered Double Hydroxides on Glassy Carbon Electrode for Enhanced Methanol Electro-oxidation. Int. J. Hydrogen Energy, 37: 9324-9329.

[54] Li, W., Xin, Q., Yan, Y. (2010). Nanostructured Pt-Fe/C Cathode Catalysts for Direct Methanol Fuel Cell: The Effect of Catalyst Composition. Int. J. Hydrogen Energy, 35: 2530-2538.

[55] Wang, Y., Zhang, D., Peng, W., Liu, L., Li, M. (2011). Electrocatalytic Oxidation of Methanol at Ni-Al Layered Double Hydroxide Flm Modified Electrode in Alkaline Medium. Electrochim. Acta, 56: 5754-5758.

[56] Lee, S., Kim, H.J., Choi, S.M., Seo, M.H., Kim, W.B. (2012). The Promotional Effect of $\mathrm{Ni}$ on Bimetallic PtNi/C Catalysts for Glycerol Electrooxidation. Appl. Catal. A-Gen., 429-430:39-47.

[57] Li, Y., Gao, W., Ci, L., Wang, C., Ajayan, P.M. (2010). Catalytic Performance of Pt Nanoparticles on Reduced Graphene Oxide for Methanol Electro-oxidation. Carbon, 48:1124-1130.

[58] Chen, J.H., Wang, M.Y., Liu, B., Fan, Z., Cui, K.Z., Kuang, Y.F. (2006). Platinum Catalysts Prepared with Functional Carbon Nanotube Defects and its Improved Catalytic Performance for Methanol Oxidation. J. Phys. Chem. B, 110: 11775-11779.

[59] Kua, J., III. Goddard, W.A. (1999). Oxidation of Methanol on $2^{\text {nd }}$ and $3^{\text {rd }}$ Row Group VIII Transition Metals (Pt, Ir, Os, Pd, Rh, and $\mathrm{Ru}$ ): Application to Direct Methanol Fuel Cells. J. Am. Chem. Soc., 121:10928-10941.

[60] Wang, H., Xiang, X., Li, F. (2010). Facile Synthesis and Novel Electrocatalytic Performance of Nanostructured Ni-Al Layered Double Hydroxide/carbon Nanotube Composites. J. Mater. Chem., 20:3944-3952.

[61] Taraszewska, J., Goslonek, G. (1994). Electrocatalytic Oxidation of Methanol on a Glassy Carbon Electrode Modified by Nickel Hydroxide Formed by Ex Situ Chemical Precipitation. J. Electroanal. Chem., 364:209-213.

[62] Singh, R.N., Singh, A., Mishra, D., Anindita Chartier, P. (2008). Oxidation of Methanol on Perovskite-type $\mathrm{La}_{2-\mathrm{x}} \mathrm{Sr}_{\mathrm{x}} \mathrm{NiO}_{4}(0 \leq \mathrm{x} \leq 1)$ Film Electrodes Modified by Dispersed Nickel in 1 M KOH. J. Power Sources, 185: 776-783. 
[63] Habibi, E., Razmi, H. (2012). Glycerol Electrooxidation on $\mathrm{Pd}, \mathrm{Pt}$ and $\mathrm{Au}$ Nanoparticles Supported on Carbon Ceramic Electrode in Alkaline Media. Int. J. Hydrogen Energy, 37: 16800-16809.

[64] Raoof, J.-B., Hosseini, S.R., Rezaee, S. (2014). Preparation of Pt/poly (2-Methoxyaniline)Sodium Dodecyl Sulfate Composite and its Application for Electrocatalytic Oxidation of Methanol and Formaldehyde. Electrochim. Acta, 141: 340-348.

[65] Habibi, B., Pournaghi-Azar, M.H., Abdolmohammad-Zadeh, H., Razmi, H. (2009). Electrocatalytic Oxidation of Methanol on Mono and Bimetallic Composite Films: Pt and Pt-M $(\mathrm{M}=\mathrm{Ru}$, Ir and Sn) Nano-particles in Poly(oaminophenol). Int. J. Hydrogen Energy, 34: 2880-2892.

[66] Habibi, B., Dadashpour, E. (2013). Carbonceramic Supported Bimetallic Pt-Ni Nanoparticles as an Electrocatalyst for Electrooxidation of Methanol and Ethanol in Acidic Media. Int. J. Hydrogen Energy, 38: 5425-5434.

[67] Khorasani-Motlagh, M., Noroozifar, M., Ekrami-Kakhki, M.-S. (2011). Investigation of the Nanometals ( $\mathrm{Ni}$ and $\mathrm{Sn}$ ) in Platinum Binary and Ternary Electrocatalysts for Methanol Electrooxidation. Int. J Hydrogen Energy, 36: 11554-11563.

[68] He, W., Jiang, H., Zhou, Y., Yang, S., Xue, X., Zou, Z., Zhang, X., Akins, D.L., Yang, H. (2012). An Efficient Reduction Route for the Production of Pd-Pt Nanoparticles Anchored on Graphene Nanosheets for Use as Durable Oxygen Reduction Electrocatalysts. Carbon, 50: $265-274$.
[69] Habibi, B., Mohammadyari, S. (2015). Facile Synthesis of Pd Nanoparticles on Nano Carbon Supports and their Application as an Electrocatalyst for Oxidation of Ethanol in Alkaline Media: The Effect of Support. Int. J. Hydrogen Energy, 40: 10833-10846.

[70] Habibi, B., Ghaderi, S. (2015). Synthesis, Characterization and Electrocatalytic Activity of Co@Pt Nanoparticles Supported on Carbon-Ceramic Substrate for Fuel Cell Applications. Int. J. Hydrogen Energy, 40: 51156125 .

[71] Wu, H., Wexler, D., Liu, H. (2011). Durability Investigation of Graphene-supported $\mathrm{Pt}$ Nanocatalysts for PEM Fuel Cells. J. Solid State Electrochem., 15: 1057-1062.

[72] Zhao, J., Shao, M., Yan, D., Zhang, S., Lu, Z., Li, Z., Cao, X., Wang, B., Wei, M., Evans, D.G., Duana, X. (2013). A Hierarchical Heterostructure Based on $\mathrm{Pd}$ Nanoparticles/layered Double Hydroxide Nanowalls for Enhanced Ethanol Electrooxidation. J. Mater. Chem. A, 1: 5840-5846.

[73] Ding, K., Liu, L., Cao, Y., Yan, X., Wei, H., Guo, Z. (2014). Formic Acid Oxidation Reaction on a PdxNiy Bimetallic Nanoparticle Catalyst Prepared by a Thermal Decomposition Process Using Ionic Liquids as the Solvent. Int. J. Hydrogen Energy, 39: 7326-7337.

[74] He, P., Wang, X., Liu, Y., Liu, X., Yi, L. (2012). Comparison of Electrocatalytic Activity of Carbon-supported Au@M (M=Fe, Co, $\mathrm{Ni}, \mathrm{Cu}$ and $\mathrm{Zn}$ ) Bimetallic Nanoparticles for Direct Borohydride Fuel Cells. Int. J. Hydrogen Energy, 37: 11984-11993. 